
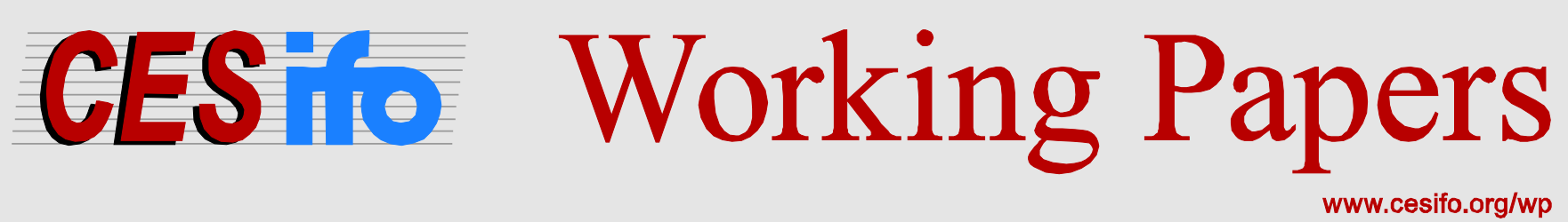

\title{
The Selection Effect and the Inflation-Output Variability Trade-off
}

\author{
Engin Kara
}

\author{
CESIFO WORKING PAPER NO. 5664 \\ CATEGORY 7: MONETARY POLICY AND INTERNATIONAL FinANCE \\ DECEMBER 2015
}

An electronic version of the paper may be downloaded

- from the SSRN website: Www.SSRN.com

- from the RePEc website: Www.RePEc.org

- from the CESifo website: www.CESifo-group.org/wp 


\title{
The Selection Effect and the Inflation-Output Variability Trade-off
}

\begin{abstract}
It has been shown that extending the Calvo model to account for the heterogeneity in price stickiness suggested by the micro-evidence significantly improves the performance of the model. In the new model, price-changing firms are chosen disproportionately from sectors with more flexible prices. In this paper, I show that this selection effect significantly affects policy conclusions that arise from the model. In the new model, the level and the variability of inflation is higher than in the Calvo model with no selection effect. Attempting to lower inflation's variability results in a significant increase output's variability, without changing inflation's variability much.
\end{abstract}

JEL-Codes: E000.

Keywords: DSGE models, selection effect, variance trade-off, Multiple Calvo, Calvo.

\section{Engin Kara}

Department of Economics

University of Ozyegin

Istanbul / Turkey

engine.kara@ozyegin.edu.tr 


\section{Introduction}

Understanding the mechanisms at work in the time-dependent sticky price models and their implications for the design of optimal monetary is important, since these models are predominant in the monetary economics literature and since they are used at central banks around the world for monetary policy analysis and forecasting. Recent work in monetary economics has made progress in this by identifying a distinct mechanism that derives the main properties of the sticky price models. It has been shown that selection effects play a crucial role in time-dependent sticky price models (see Carvalho and Schwartzman (2015) and Kara (2015)). In such models, "selection effects" are based on the duration of price stickiness. A smaller selection effect means that firms that reset their prices long time ago are less likely to adjust their prices.

A natural question arises: can the concept of selection effect help to generate new insights in the design of optimal monetary policy? The answer to this question is yes. Before explaining how, let me briefly describe how the selection effect affects the aggregate dynamics in the sticky price models. Carvalho and Schwartzman (2015) show that the real effects of monetary policy depend on selection effects. If the selection effect is small, an increase in money supply has a longer lasting effects on output. This finding is intuitive. A smaller selection effect implies that fewer firms with long term contracts adjust their prices in each period. As a result, the adjustment in prices is delayed, resulting in a sluggish adjustment in output. Findings reported in Kara (2015) emphasises another channel through which the selection effect affects aggregate dynamics. Kara (2015) extends the popular Calvo pricing 
model within the Smets and Wouters (2007). As is well-known, Calvo pricing assumes that price-changing firms are chosen randomly. So there is no selection effect. Accounting for the heterogeneity in price stickiness suggested by the micro-evidence results in a smaller selection, as in the Multiple Calvo (MC) model price-changing firms are drawn mostly from sectors with higher hazards rates ${ }^{23}$. With lower degree of price stickiness, these firms react more to shocks, resulting in a more volatile aggregate inflation in the MC than in the Calvo model. The volatility of inflation in the $\mathrm{MC}$ is more consistent with the volatility of actual inflation, whereas, as is well-known (see Chari et al. (2009)), the Calvo model relies on exogenous price shocks to match the volatility of actual inflation. As these findings clearly show, the presence of a smaller selection effect helps the model to match the key features of the aggregate data.

To examine the implications of the selection effect on the design of optimal monetary policy, the MC model is employed. The design of optimal monetary policy in this paper follows the Ramsey approach, according to which the central bank maximises households' welfare subject to the equilibrium conditions of the model. The welfare function is derived by taking the secondorder approximation of the representative household's utility function. In the

\footnotetext{
${ }^{2}$ Carvalho (2006) outlines and describes the MC model in detail.

${ }^{3}$ Carvalho and Schwartzman (2015) show that their findings also hold in the Taylor pricing model and in the sticky information model model of Mankiw and Reis (2002). In the Taylor model the selection effect is larger than that in the Calvo model. For this reason, in the Multiple Calvo Economy the selection effect is smaller than that of the Generalised Taylor Economy of Dixon and Kara (2010).
} 
MC, the welfare function depends on output variability, inflation variability in each sector and relative prices. Cost-push shocks are assumed. As is well known, such shocks generate a policy trade-off between price stability and output stability.

The results reported in the paper suggest that the selection effect significantly affects the policy conclusions that arise from the models. Several interesting results emerge from the analysis:

- The optimal level and the volatility of inflation in the MC are higher than those in the Calvo model.

- A smaller selection effect increases welfare losses.

- Under the optimal policy, the required fall in output to control inflation decreases as the selection effect becomes smaller, implying that policy trade-off between inflation and output is easier in the MC.

- Attempting to lower the volatility of inflation below the optimal level comes at the cost of substantially higher volatility of output, without changing inflation's volatility much.

The intuition behind the results can be easily understood by considering two two-sector economies with distributions of price spells that are meanpreserving spread of each other. A higher mean preserving spread results in more flexible prices in the sector with relatively price more flexible and stickier prices in the other sector. Increased price flexibility in the sector with relatively flexible prices means that prices change more when the shock hits the economy. Increased price stickiness in the sticky price sector results in a 
more sluggish adjustment of prices. As a result, the impulse response function (IRF) of inflation under the optimal policy in the MC are larger than those in the Calvo model. Increased price stickiness in the sticky sector also means that firms make larger price adjustments when resetting their prices, as they have to keep the same price for longer. This increases the volatility of inflation in the sticky price sector and, consequently, of aggregate inflation. Increased price flexibility in the other sector lowers inflation's volatility. Since price dispersion increases exponentially in Calvo pricing, the sticky price sector dominates, leading to higher welfare losses.

Findings further suggest that the optimal level of output volatility decreases, as the selection effect becomes smaller. This is mainly because of the fact that, since prices in the sector with relatively flexible prices become more flexible, the output gap at the sectoral level and, consequently, at the aggregate level closes faster. As a result, the initial fall in output is smaller in the $\mathrm{MC}$ than in the Calvo model, although the response is persistent. Finally, to understand the reason why lowering the volatility below the optimal level is very costly, first note the loss function in the MC depends not only the variability of inflation and output, but also the variability of relative prices. In response to a cost-push shock, prices in the sticky sector do not change much, while those in the relatively flexible sector changes a lot. This difference results in an increase in relative prices, leading to an increase in the volatility of inflation in the sector with relatively flexible prices and, therefore, in the volatility of aggregate inflation. This increased volatility of inflation makes the real interest rate and, consequently, output more volatile. I present cases in which, when the selection effect is sufficiently small, lowering inflation's 
volatility increases the volatility of both inflation and output.

The remainder of the paper is organised as follows. Section 2 presents the model and derives a utility function based loss function for the central bank. This section also discusses the calibration of the model parameters. Section 3 examines the implications of the selection effect on optimal monetary policy design. Section 4 compares the Taylor curves implied by the MC calibrated according to the Bils and Klenow (2004) with its standard one sector counterparts. Finally, Section 5 concludes the paper. The Matlab/Dynare codes used to generate the results are available in an online appendix.

\section{The Model}

Two models of price setting are considered: the standard Calvo model and the Multiple Calvo model (MC). The MC approach extends the standard Calvo model to account for the heterogeneity in price stickiness. There is a continuum of firms, indexed by $f \in(0,1)$. A typical firm is standard new-Keynesian: it has a monopoly power over a specific product, for which the demand has a constant price elasticity $(\theta)$. It operates a technology, $Y_{f t}=L_{f t}$; that transforms labour $\left(L_{f t}\right)$ into output $\left(Y_{f t}\right)$. These products are then combined, according to a CES (or Dixit-Stiglitz) aggregator, to produce the final consumption good $Y_{t}$. Finally, the unit interval of firms are divided into segments corresponding to sectors. There are $N$ sectors, $i=1: N$, with sector shares $\left(\alpha_{i}\right)$ summing to unity. Sectors differ in their shares and contract lengths. Firms within a sector face the same Calvo hazard rate $\left(\omega_{i}\right)$. Assuming that all the sectors face the same hazard rate $(\omega)$ gives the standard Calvo model. The rest of the models are standard 
New Keynesian (see Woodford (2003), Chapter 3). There is a continuum of identical and infinitely lived households, who derive utility from consumption and leisure. The central bank conducts monetary policy. The log-linearized model equations are summarised below. The sectoral output level $y_{i t}$ can be expressed as a function of the sectoral price $p_{i t}$ relative to the aggregate price level $p_{t}$ and aggregate output $y_{t}$ :

$$
y_{i t}=-\theta\left(p_{t}-p_{i t}\right)+y_{t}
$$

The Euler condition from the representative household's consumption is given by

$$
y_{t}=E_{t} y_{t+1}-\frac{1}{\sigma}\left(r_{t}-E_{t} \pi_{t+1}\right)
$$

where $r_{t}$ is the interest rate, $\pi_{t}=p_{t}-p_{t-1}$ is the inflation rate and $\sigma$ denotes the representative household's relative risk aversion. The pricing rule for firms in sector $i$ is

$$
x_{i t}=\omega_{i}\left(p_{t}+\gamma y_{t}\right)+\left(1-\omega_{i}\right) \beta E_{t} x_{i t+1}
$$

where $\gamma=\frac{\sigma+\eta_{l}}{1+\theta \eta_{l}}$. $\quad \theta$ is the elasticity of substitution between different goods and $\eta_{l}$ is the inverse of the labour supply elasticity. The corresponding price index is given by

$$
p_{i t}=\omega_{i} x_{i t}+\left(1-\omega_{i}\right) p_{i t-1}
$$

Combining these two equations gives the Phillips curve in sector $i$

$$
\pi_{i t}=E_{t} \pi_{i t+1}+\kappa \gamma\left(y_{t}-\bar{p}_{i t}\right)+e_{t}
$$

where $\kappa=\frac{\omega_{i}\left(1-\beta\left(1-\omega_{i}\right)\right)}{\left(1-\omega_{i}\right)}, \pi_{i t}=p_{i t}-p_{i t-1}$ is the sectoral inflation rate in sector $i$ and $\bar{p}_{i t}=p_{i t}-p_{t}$ is the relative sectoral prices

$$
\sum_{i=0}^{N} \alpha_{i} \bar{p}_{i t}=0
$$


Finally, $e_{t}$ is a cost push shock, which is appended to the sectoral Phillips curves. It is assumed to follow an $\mathrm{AR}(1)$ process

$$
e_{t}=\rho^{e} e_{t-1}+\sigma_{t}^{e}
$$

where $\rho^{e}$ is the persistence parameter in the shock process and $\sigma_{t}^{e}$ is an i.i.d. shock, with zero mean and finite variance.

\subsection{Welfare Function}

Following Woodford (2003), a welfare function is derived for the central bank by taking a second order approximation of the representative household's utility function. The welfare function is given by ${ }^{4}$

$$
W_{t}=-\frac{1}{2} U_{C}(C) C L_{t}+t . i . p
$$

where $\mathrm{C}$ is the steady state consumption, $U_{C}$ is the marginal utility of consumption and t.i.p collects all the terms that are independent of policy. The loss function is given by

$$
L_{t}=\bar{\alpha} y_{t}^{2}+\frac{\theta}{\kappa_{i}} \sum_{i=1}^{N} \alpha_{i} \pi_{i t}^{2}+\theta \sum_{i=1}^{N} \alpha_{i} \bar{p}_{i t}
$$

where $\bar{\alpha}=\left(\sigma+\eta_{l}\right)$. This expression shows that the loss function depends on output and inflation variability, as in the standard model, and the sectoral relative price variability.

\subsection{Calibration}

Following the literature (e.g. Walsh (2005) and Woodford (2003)), $\theta$ is set to $7.88, \sigma$ is set to $0.16, \eta_{l}$ is set to 1.2 and $\omega$ is set to 0.25 . The discount

\footnotetext{
${ }^{4}$ In deriving this function, I follow the steps in Gali and Monacelli (2005).
} 
factor assumed is $\beta=0.99$. These assumptions generate a Phillips curve slope $(\gamma \kappa)$ of around 0.02 , which is in line with the empirical estimates of the slope of the Phillips curve (see, for example, Smets and Wouters (2007)). I set $\rho^{e}=0.8$ and $\sigma_{t}^{e}=0.024$. In the case of the MC, sector-specific hazard rates are chosen in a way that the degree of nominal rigidity in the model is the same as that implied by the Calvo model. The parameterisation of the cross-sectional distribution of price stickiness will be discussed later in the text.

\section{The selection effect and optimal policy}

The optimal monetary policy is obtained by maximising the welfare level defined in Equation (8) subject to the equilibrium conditions (Equations (2), (5) and (6)). I start by comparing the impulse response functions (IRFs) of inflation and output to a cost-push shock under the optimal policy from twosector MCs with those from the standard Calvo model. Specifically, several two-sector MCs are considered. In each model, the sectors have equal shares and the overall degree of price stickiness, as measured by $\kappa=\frac{1}{2} \sum_{i=1}^{2} \frac{1}{\omega_{i}}$, is the same as that implied by the one-sector model $\left(\frac{1}{\omega}\right)$. The only difference between the models is that they differ in their relative degree of price stickiness, defined as $R S=\frac{\omega_{1}}{\omega_{2}} . R S=1$ corresponds to the standard Calvo model. Figure 1 plots the IRFs of output and inflation when $R S=1, R S=2$ and $R S=5$.

As it is evident from the figure, because of the presence of the cost push shock, there exists a trade-off between inflation and output. In all three models, inflation jumps when the shock hits the economy. To lower inflation, the 
central bank has to keep output below the steady state level for several periods. An important finding emerges from the figure. The optimal response of inflation in the two sector models is larger than in the Calvo model, suggesting that the optimal level of inflation is higher in the $\mathrm{MC}$ than in the Calvo model. The level of inflation becomes higher, as the relative degree of price stickiness increases. Turning to the the IRFs of output, we see that the response of output becomes smaller as the relative degree of price stickiness increases. For example in the case of the $\mathrm{MC}$ with $R S=5$, the cumulative loss of output in the $\mathrm{MC}$ is 2.4 , which is $30 \%$ less than that in the standard model.

These findings suggest that the volatility of inflation increases, while the volatility of output decreases, as the relative degree of price stickiness increases. Figure 2 confirms this suggestion. There reported are the standard deviations of inflation and output for different degrees of relative price stickiness.

What is the intuition behind these results? Let me first consider the output response. There are two reasons why the output response becomes smaller as the relative degree of price stickiness increases. First, in the MC optimal level of inflation is higher than in the Calvo model and increases with the mean preserving spread. As consequence, given the trade-off between inflation and output, in the MC, output does not need to fall as much as than in the Calvo model.

Second, it appears that the policy trade-off between inflation and output facing the central bank is easier in the MC than in the Calvo model in the sense in the MC inflation can be lowered without needing to disrupt output 
as much as in the Calvo model. To see this, a case in which the central bank adopts a zero inflation policy is considered. Figure 3 reports the results from this experiment. Specifically, the figure shows the standard deviations of output and inflation under the zero inflation policy.

If we compare Figure 3 with Figure 2, we see that the standard deviations of output under the zero inflation policy are much larger than those under the optimal policy. While this observation indicates that such a policy gives an outcome far from the optimum, Figure 3 clearly shows that the required fall in output to achieve zero inflation is lower in the $\mathrm{MC}$ and becomes smaller as the relative degree of price stickiness increases. The intuition behind these results is straightforward. Introducing heterogeneity in price stickiness to the model gives rise to a smaller selection effect. This means that firms that adjust their prices in a given period are mostly chosen from sectors with higher hazard rates. As a consequence, the beginning of the price adjustment process is driven by the sectors with higher hazard rates. This feature of the model has an important implication for optimal policy and can be easily understood by considering Equation (1). For convenience, it is repeated here

$$
y_{i t}-y_{t}=-\theta\left(p_{t}-p_{i t}\right)
$$

This equation shows that the output gap (i.e. $y_{i t}-y_{t}$ ) in sector $i$ depends on the relative prices in that sector. Given the fact that prices adjust faster in the sector with higher hazard rates and that the earlier part of the adjustment process is dominated by the this sector, the output gap in this sector is closed faster. Therefore, compared to the Calvo model, in the MC the adjustment to shocks is faster. The fact that the variability of output gap becomes smaller as the relative degree of price stickiness increases reinforces this intuition. 
Increased selection effect means prices in the sector with relatively flexible prices become more flexible, resulting in a faster adjustment in the output gap (i.e. $y_{i t}-y_{t}$ ) in the sector with relatively flexible prices and, therefore, in aggregate output.

Next, the optimal response of inflation is considered. The optimal level and variability of inflation is higher in the $\mathrm{MC}$ than in the Calvo model. Let me first explain why the inflation response becomes larger with a smaller selection effects. As the mean preserving spread increases, prices in the sticky price sector becomes stickier and take longer to adjust. Prices in the relatively flexible sector becomes more flexible. With lower degree of price stickiness, these firms react more to shocks. This explains why the initial response is larger in the MC. It also explains why the initial response becomes larger as the relative degree of price stickiness increases. Because of the presence of longer-term contracts, the response is more persistent.

Why are the welfare losses larger in the MC? To understand the reasons for this result first note that firms that reset their prices less frequently tend to make larger changes to prices, since they take into account the fact that they will have to charge the same price for a longer period of time. Since prices in the sticky price sector becomes stickier with an increase in mean preserving spread, the volatility of inflation in this sector increases. With the same reasoning, the volatility of inflation in the sector with relatively flexible prices decreases. The increased volatility of inflation in the sticky price sector leads to an increase in aggregate inflation, while the decreased volatility in the other sector has the opposite effect. The sticky sector dominates since, with Calvo pricing, price dispersion increases exponentially with price stickiness. 
Figure 4a. confirms these suggestions. There reported are the standard deviations of sectoral inflation rates and of aggregate inflation. As it is evident from the figure, an increase in the relative price stickiness increases inflation's variability in the sticky price sector, while there is a smaller fall in the volatility of inflation in the sector with relatively flexible prices. Increased volatility in the sticky price sector increases the volatility of inflation and, leading to larger welfare losses.

\section{A variance trade-off between price inflation and output}

The findings reported so far have seemed to suggest that the Taylor curves in the MC and standard Calvo models may be different. The concept of Taylor curves is put forward by John Taylor (1979) and graphically shows the possible combinations of output volatility and inflation volatility from which the central bank can choose. The curve is computed by calculating the standard deviations of output and inflation under the optimal policy at different relative preferences for inflation versus output. This is achieved by varying the weight on output variability in the loss function (i.e. $\bar{\alpha}$ ) in equation (8) and for each case calculating the standard deviations of output and inflation.

Figure 5 plots the Taylor curves implied by the models with the same degree of nominal rigidity but different degrees of relative price stickiness. In the figure, the $y$-axis on the right hand side shows the volatility of output, the $\mathrm{y}$-axis on the right hand side shows the weight on output in the loss function and $\mathrm{x}$-axis shows the volatility of inflation. Let me first consider the Calvo case (i.e. $R S=1$ ). As the figure indicates, the curve is downward 
sloping, meaning that reducing the variability of inflation comes at the cost of higher variability of output. However, the shape of the curve changes dramatically as the relative degree of price stickiness increases. For example, when $R S=3$, the curve becomes sort of a L-shaped curve. This means that lowering inflation's volatility below a certain level is not possible and attempting to do so only increases the volatility of output. When $R S=5$, trying to eliminate the volatility of inflation increases the volatility of both inflation and output.

To understand the reasons behind the results first note that as $\bar{\alpha}$ decreases, price stability becomes more important, reducing the importance of output stability. Consequently, the central bank increases the real interest rate more, resulting in an increase in output's volatility. As equation (5) shows, sectoral inflation depends on output. While this increase in the volatility of output leads to an increase in inflation in the sector with relatively flexible prices, inflation in the sticky price sector does not change much, simply because of the fact that prices in this sector is highly sticky. The muted response of prices in the sticky price sector and the large reaction of prices in the sector with relatively flexible prices leads to an increase in the volatility of relative prices. Increased relative prices increases the volatility of inflation in the sector with relatively flexible prices further, resulting in an increase in the volatility of aggregate inflation. As a consequence, the real interest rate becomes more volatile, increasing the volatility of output. If the relative degree of price stickiness is sufficiently large (or if the selection effect is sufficiently small), as it is the case in $R S=5$, giving to more weight to price stability can lead to an increase in the volatility of both inflation and 
output.

\subsection{An application to the US}

Thus far two sector MCs are considered. While such an approach is useful in understanding the implications of heterogeneity in price stickiness for optimal policy design, a more realistic case would require to go beyond the two sector economies and consider models that can account for the empirically relevant distribution of price contracts. To address this concern, the Taylor curve is computed in a MC calibrated according to a distribution of price spells suggested by the Bils and Klenow (2004) (BK).

Figure 6 reports the Taylor curve implied by the BK-MC and the Calvo model. The figure confirms the main finding of the paper that adding heterogeneity in the standard model has significant implications for the policy trade-off between inflation and the output. As the figure shows, the Taylor curve suggested by the BK-MC is dramatically different from the one suggested by the Calvo. Reflecting the finding that the volatility of inflation is higher in the $\mathrm{MC}$, the curve in the SW-MC is further away from the origin than that in the Calvo model. Again reflecting the findings reported earlier, the curve in the BK-MC becomes steeper as the standard deviation of inflation decreases, meaning that the cost of achieving this is higher in the BK-MC than in the Calvo model.

\section{Summary and Conclusions}

I have examined the optimal monetary implications of the selection effect by using the MC approach of modelling price stickiness. This MC approach extends the Calvo model to account for the heterogeneity in price stickiness 
suggested by the micro-evidence. In the Calvo model, there is no selection effect, as firms that adjust their prices in each period are randomly chosen. In the MC, the selection effect is smaller since firms that adjust their prices are mainly chosen from sectors with more flexible prices. As a consequence of this selection effect, the earlier part of the price adjustment process is dominated by the sectors with higher hazard rates, while the later part of the process is mainly determined by the sticky price sectors. While the existing literature tends to focus on the latter implication of the heterogeneity in price stickiness, both of these features affect the policy conclusions of the model. I consider simple two sector MCs as well as a more realistic case by calibrating it to the distribution of price spells suggested by the Bils and Klenow (2004) dataset. The results from the analysis are as follows.

First, unavoidable welfare losses increases as the selection effect becomes smaller. With a smaller selection effect, prices in the sectors with relatively sticky prices becomes stickier, while those in the other sector becomes more flexible. Increased flexibility of prices implies faster adjustment in the economy, the second effect suggests a more sluggish adjustment. The latter effect dominates since price dispersion increases exponentially with price stickiness, leading to larger welfare losses.

Second, as a consequence of the first result, the volatility and level of inflation increases as the selection effect becomes smaller. Third, under the optimal policy, the volatility of output decreases with a smaller effect. This is because, with reduced price stickiness, firms in the sector with relatively flexible prices adjust their prices faster, resulting in a faster adjustment in output. Fourth, lowering inflation's volatility becomes very difficult, if not 
impossible, as the selection effect decreases. Attempting to do so increases output's volatility without changing inflation's volatility much. This is because relative prices becomes more volatile with a smaller selection effect. More volatile relative prices leads to an increase in inflation's volatility in the sector with relatively flexible prices, resulting in an increase in aggregate inflation and that leads to more volatile real interest rate and, therefore, output.

Finally, the BK-MC is considered. Confirming the above findings, the Taylor curve implied by the BK-MC is further away from the origin than the one suggested by the corresponding Calvo model. The curve in the BK-MC is also steeper.

These findings suggest that the selection effects may have implications for the optimal inflation rate. Calculating the optimal inflation rate in the $\mathrm{MC}$ requires to explicitly incorporate positive steady-state (or trend) inflation into the model. Doing this for the Calvo model, Coibion et al. (2012) find that the Calvo model suggests an optimal inflation rate of around $2 \%$ when the zero lower bound on the nominal interest rate is taken into account, in line with the current practice of many central banks. I plan to pursue these issues in future work. 


\section{References}

Bils, M., Klenow, P., 2004. Some evidence on the importance of sticky prices. Journal of Political Economy 112 (5), 947-985.

Carvalho, C., 2006. Heterogeneity in price stickiness and the real effects of monetary shocks. Frontiers of Macroeconomics 2 (1).

Carvalho, C., Schwartzman, F. F., 2015. Selection and monetary nonneutrality in time-dependent pricing models. Journal of Monetary Economics $76,141-156$.

Chari, V. V., Kehoe, P. J., McGrattan, E. R., 2009. New Keynesian models: Not yet useful for policy analysis. American Economic Journal: Macroeconomics 1 (1), 242-66.

Coibion, O., Gorodnichenko, Y., Wieland, J., 2012. The optimal inflation rate in new keynesian models: Should central banks raise their inflation targets in light of the zlb? Review of Economic Studies 79, 1371-1406.

Dixon, H., Kara, E., 2010. Can we explain inflation persistence in a way that is consistent with the micro-evidence on nominal rigidity? Journal of Money, Credit and Banking 42 (1), 151 - 170.

Gali, J., Monacelli, T., 2005. Monetary policy and exchange rate volatility in a small open economy. Review of Economic Studies (72), 707-734.

Kara, E., 2015. The reset inflation puzzle and the heterogeneity in price stickiness. Journal of Monetary Economics 76, 29-37.

Mankiw, N. G., Reis, R., 2002. Sticky information versus sticky prices: A proposal to replace the New Keynesian Phillips curve. The Quarterly Journal of Economics 117 (4), 1295-1328. 
Smets, F., Wouters, R., 2007. Shocks and frictions in US business cycles: A Bayesian DSGE approach. American Economic Review 97 (32), 586-607. Taylor, J. B., 1979. Estimation and Control of a Macroeconomic Model with Rational Expectations. Econometrica 47 (5), 1267-86.

Walsh, C., 2005. Endogenous objectives and the evaluation of targeting rules for monetary policy. Journal of Monetary Economics 52, 889-911.

Woodford, M., 2003. Interest and prices: Foundations of a theory of monetary policy. Princeton Univeristy Press, Princeton, NJ. 

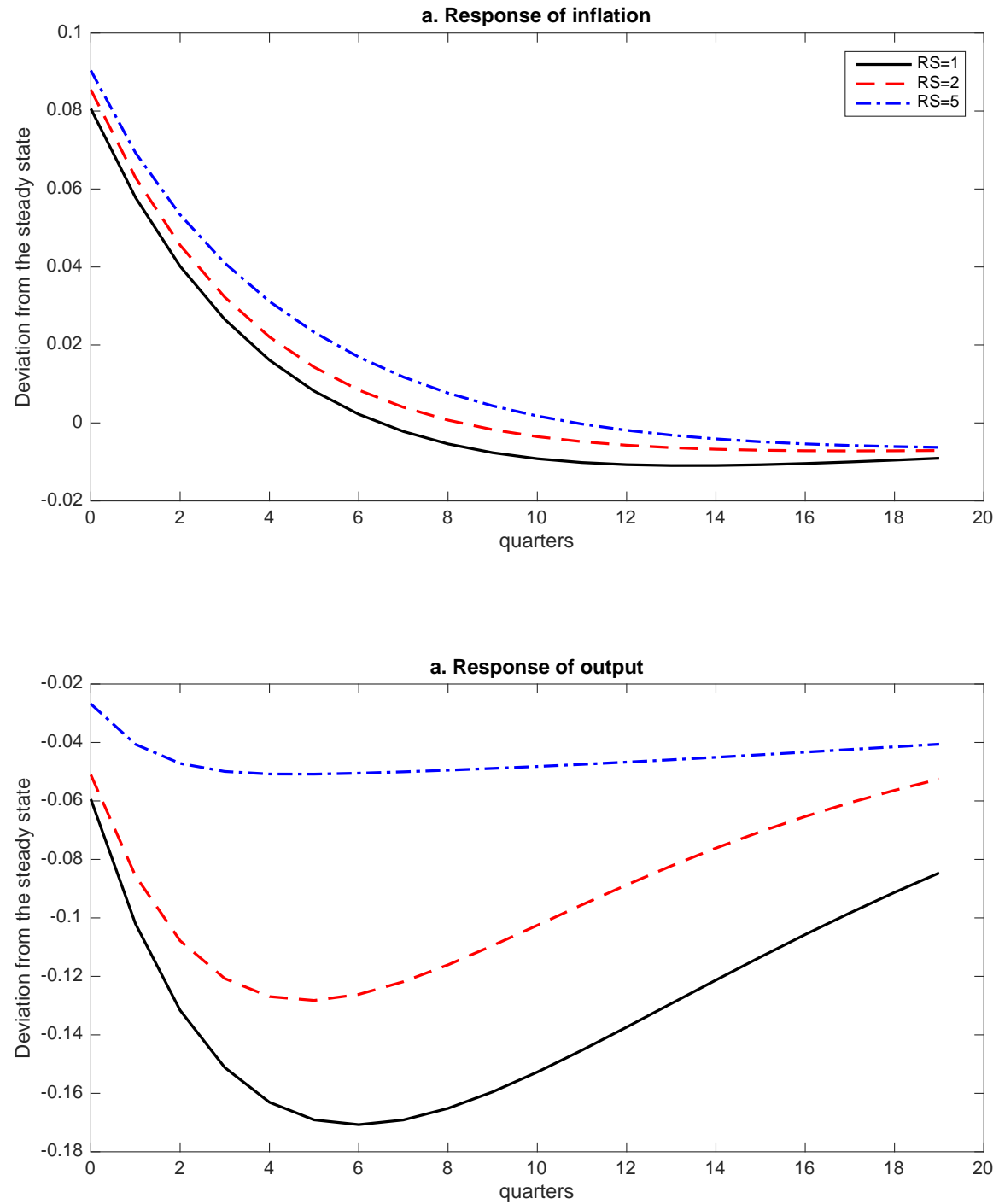

Figure 1: The impulse response functions (IRFs) of inflation and output under the optimal policy in $\mathrm{MC}$ and in the Calvo models

Notes: Plotted are IRFs of inflation and output under the optimal policy in a 2-sector MC and in the Calvo model. While the mean contract length is the same in the models, the relative degree of price stickiness is different. $\mathrm{RS}=1$ corresponds to the standard Calvo model. While the response of inflation is latger as the relative degree of price stickiness increases, the response of output in the MC model becomes smaller. 

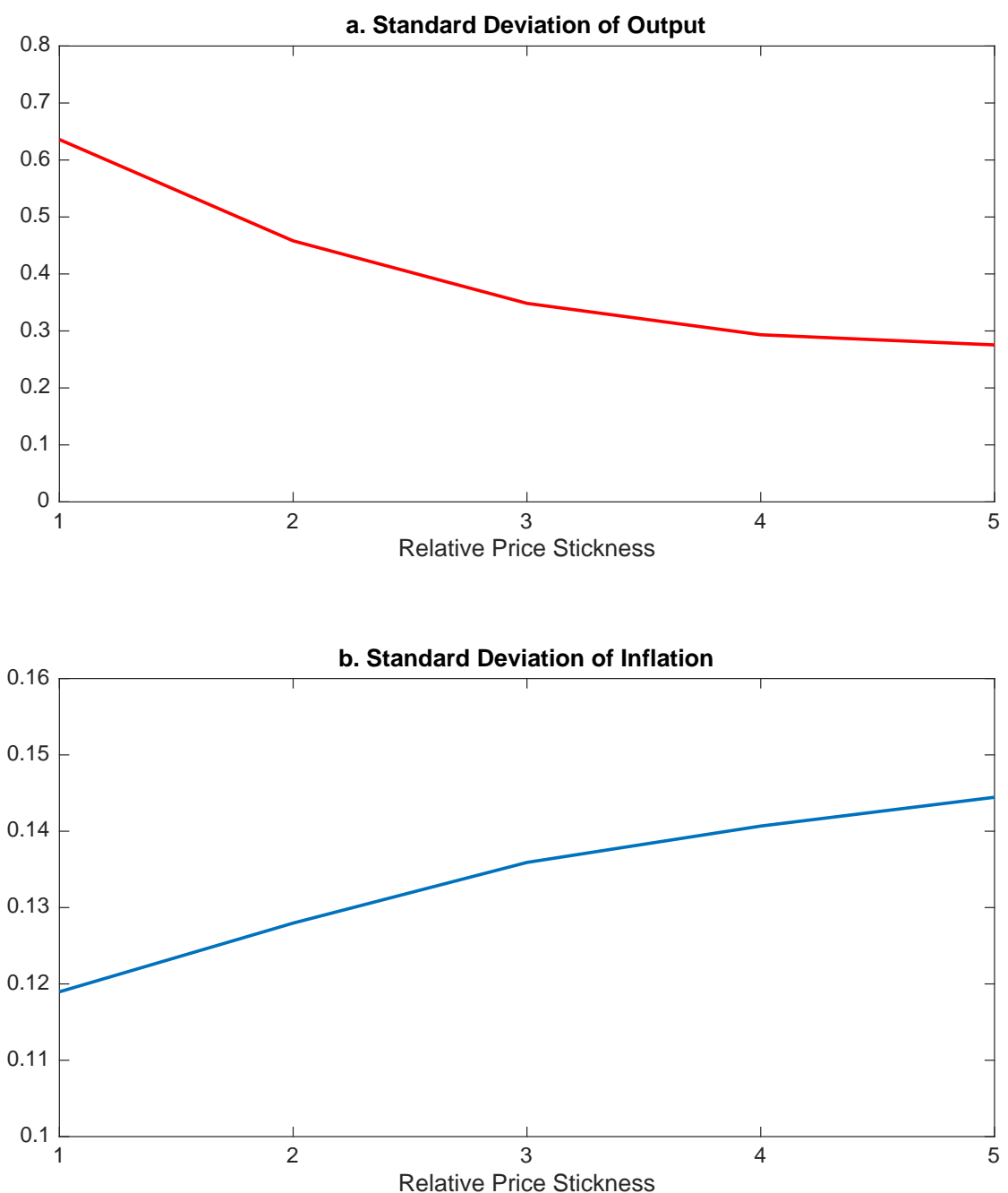

Figure 2: The standard deviations of inflation and output in two-sector MCs under the optimal policy

Notes: This figure plots the standard deviations of output (panel a) and of inflation (panel b) under the optimal policy for different degree of relative price stickiness. An increase in mean preserving spread leads to an increase in the standard deviation of inflation and reduces the standard deviation of output. 


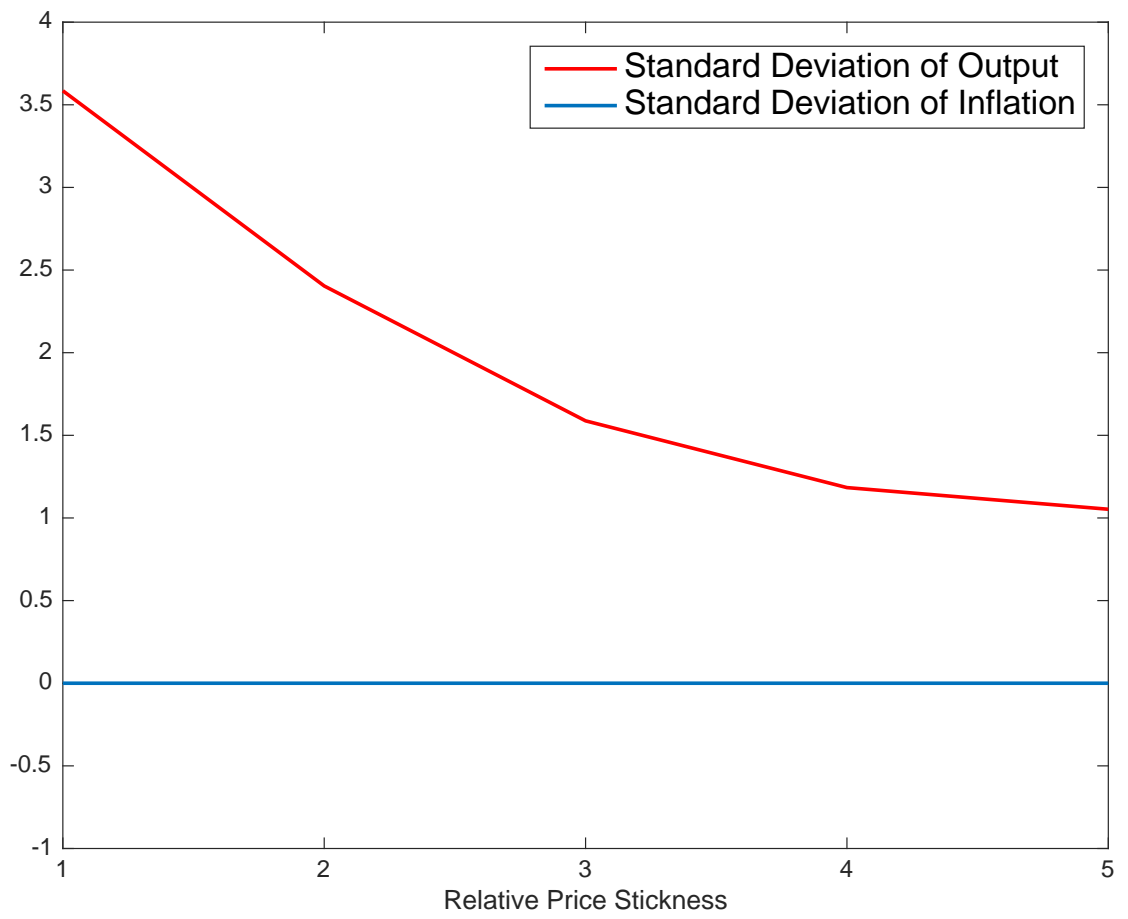

Figure 3: The standard deviation of inflation and the output gap in two-sector MCs under a zero inflation policy

Notes: This figure repeats the same experiment in the previous figure by assuming that the central bank adopts a zero inflation policy. A mean preserving spread reduces the standard deviation of output. 
(a)

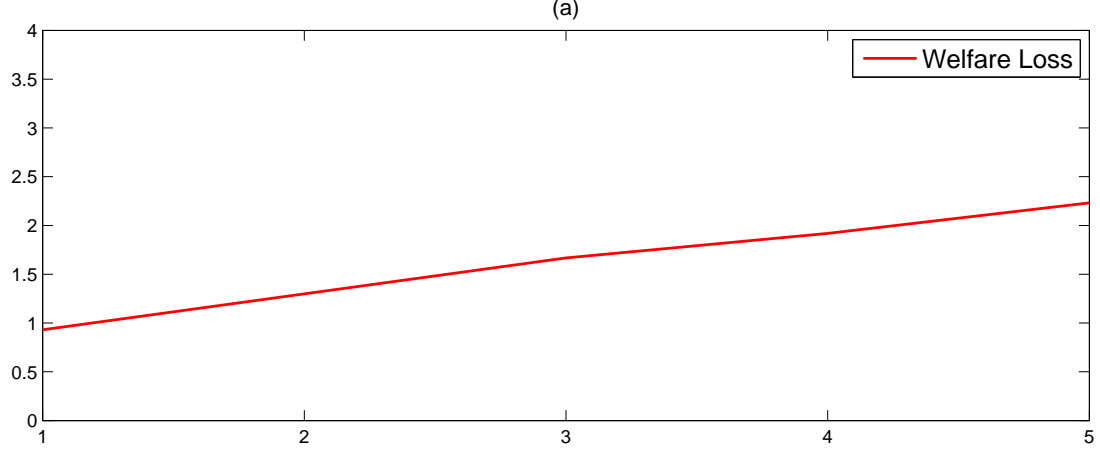

(b)

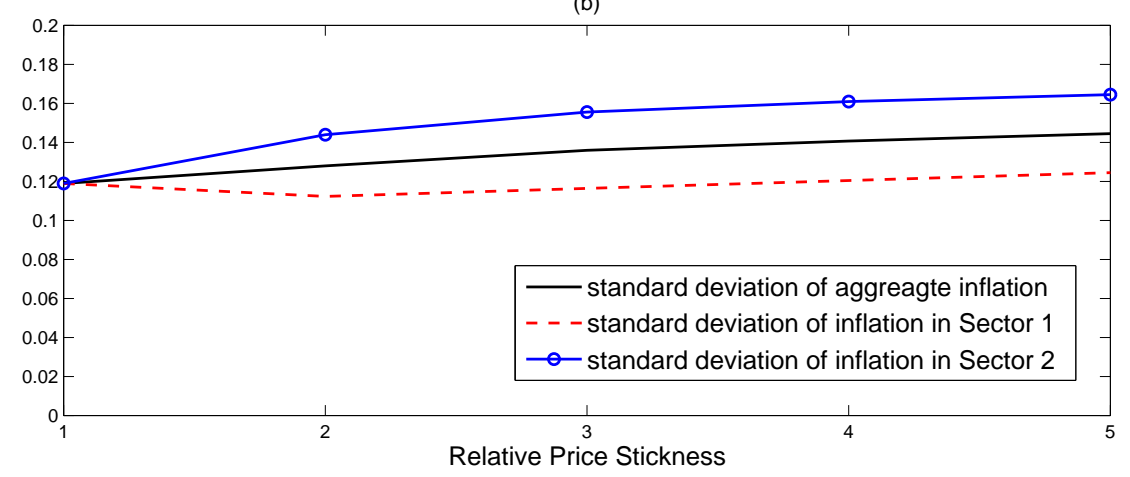

Figure 4: Welfare Losses under different relative degree of price stickiness

Notes: In Sector 1 prices are more flexible than in Sector 2. Panel (a) shows that an increase in mean preserving spread increases unavoidable losses. Panel (b) shows that this is true since an increase in mean preserving spread makes prices in the sticky sector stickier, resulting in a more volatile inflation in this sector and, consequently, in aggregate inflation. 


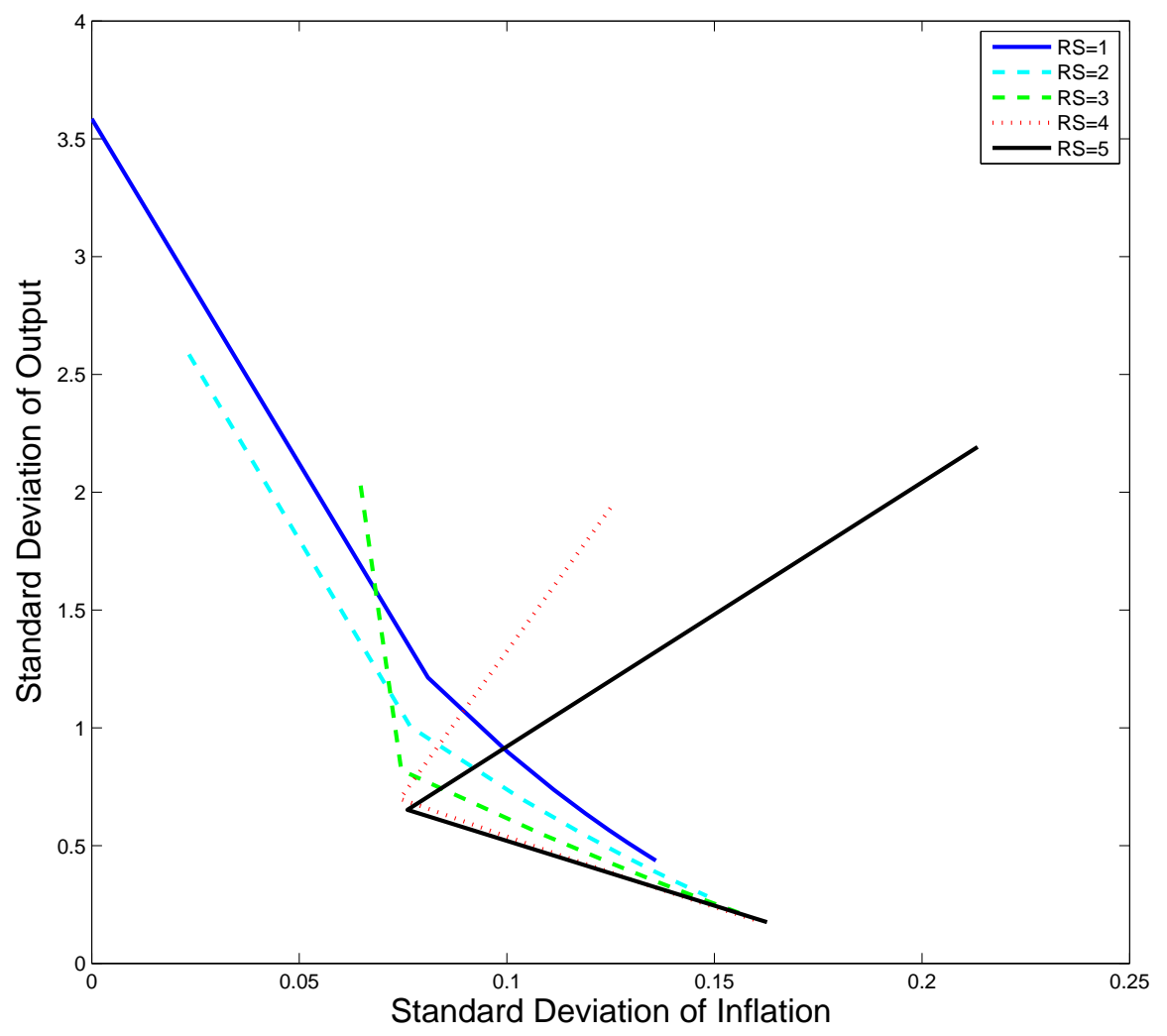

Figure 5: The Taylor Curves under different relative degree of price stickiness Notes: This figure shows that the Taylor Curves in two-sector MCs. An increase in mean preserving spread changes the curves dramatically. 


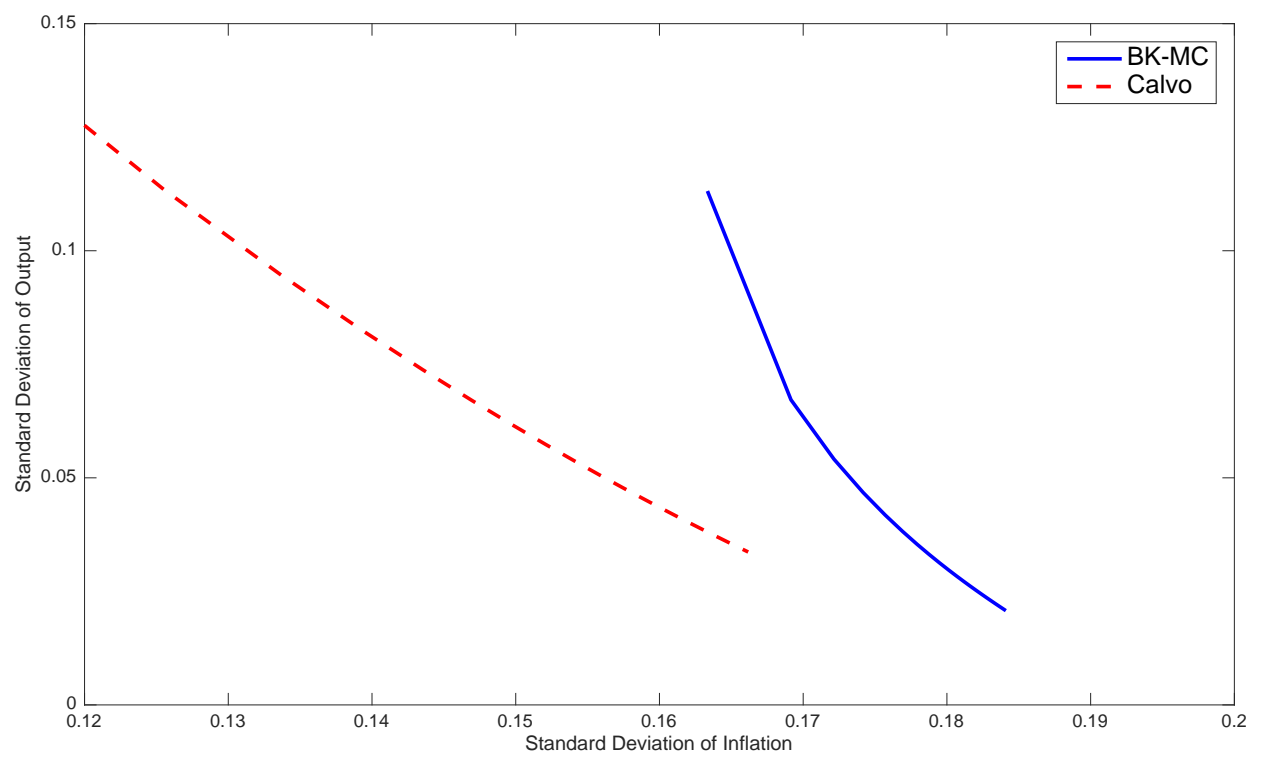

Figure 6: The Taylor Curves in Bils and Klenow (2004) (BK)-MC and in the standard Calvo model.

Notes: The Taylor curve in the BK-MC is steeper and further away from the origin than that in the Calvo model. The optimal level of inflation volatility is higher and lowering inflation's volatility is more costly in the BK-MC than in the Calvo model. 